\title{
Research on the Present Situation of China's Natural Drinking Water Industry Standards
}

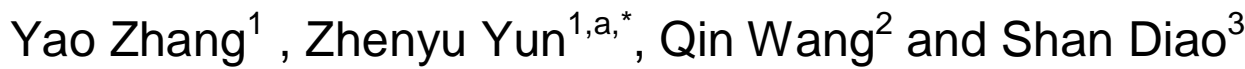 \\ ${ }^{1}$ China National Institute of Standardization, Haidian District, Beijing, China \\ 2 Tibet Institute of Standardization, Lhasa, Tibet Autonomous Region \\ ${ }^{3}$ Tibet Autonomous Region Market Supervision Bureau, Lhasa, Tibet Autonomous Region \\ ayunzy@cnis.gov.cn \\ ${ }^{*}$ Corresponding author
}

Keywords: Natural drinking water, Industry process, Standards.

\begin{abstract}
Based on the relevant standards of China's natural water industry, this paper defines the concept and classification of natural drinking water, and divides each production link of natural drinking water industry. In addition, this paper also analyzes the pre-production link standards of natural drinking water from the aspects of investigation \& exploration, monitoring \& evaluation, comprehensive protection, and development \& utilization of water resources separately, analyzes the in-production link standards in terms of packaging materials production, processing equipment manufacturing, product production \& processing, and process quality control, analyzes the post-production link standards with regard to the inspection \& testing, storage \& logistics, allocation $\&$ distribution, and brand building, and points out the weak links of the standard system of natural drinking water industry, which is of great significance to the product quality improvement, inspection \& supervision, and brand building of natural drinking water industry.
\end{abstract}

\section{Introduction}

At present, China is the world's largest consumer of packaged drinking water, with a market size of over 100 billion Yuan and an average annual demand growth rate of over 15\%, which is much higher than that of developed countries ${ }^{[1]}$. As the main branch of packaged drinking water, natural drinking water features the rapid expansion of industrial scale, strong market demand, high added value and etc., and has the broad market prospects. However, there are still problems such as vague definition of product concept, confusion of standards, low brand value, insufficient recycling of plastic solid waste and etc. ${ }^{[2-4]}$, which affects the further development of natural drinking water industry. Therefore, this paper divides the natural drinking water industry into three links, namely, pre-production, in-production and post-production, summarizes the standards involved in each link, and targetedly points out the weak links of the standard system of the natural drinking water industry, which is of great significance to the product quality improvement, inspection \& supervision, and brand building of natural drinking water industry.

\section{Definition and classification of natural drinking water in China}

Based on the classification and definition of GB 19298-2014 National Food Safety Standard Packaged Drinking Water, GB 8537-2008 Drinking Natural Mineral Water and GB/T 10789-2015 General Rules for Beverages and other relevant standards ${ }^{[5-7]}$, Packaged drinking water is water that is directly sourced from surface, underground or public water supply systems, and is processed and sealed in containers for direct drinking, including drinking natural mineral water, drinking purified water and other drinking water (drinking natural spring water, drinking natural water and other drinking water). According to the document Opinions on Accelerating the Development of Natural Drinking Water Industry and the group standard T/ZTSXH001S-2016 Tibet Autonomous Region Group Standard Tibetan Drinking Natural Water in Tibe ${ }^{[8]}$, and based on the characteristics of natural drinking water sources, natural drinking water can be considered as water that is processed into the 
water directly drunk in containers, including drinking natural mineral water, drinking natural spring water and drinking natural water, instead of passing through a public water supply system. Among them, drinking natural mineral water is water that gushes out naturally from deep underground or is collected by drilling wells, contains a certain amount of minerals, trace elements or other components, and is not polluted in a certain area where the preventive measures are taken to avoid pollution. Generally, its chemical composition, flow rate, water temperature and other dynamic indicators are relatively stable within the natural periodic fluctuation range. According to the content of carbon dioxide, it can be divided into aerated natural mineral water, carbonated natural mineral water, noncarbonated natural mineral water and deaerated natural mineral water. Drinking natural spring water is the natural water sourced from the natural spring water gushing from underground or underground spring water collected by drilling wells, which has not passed through public water supply system. Under normal circumstances, its chemical composition, flow rate, water temperature and other dynamic indicators are relatively stable within the natural periodic fluctuation range. Drinking natural water is a product made of water from natural sources such as wells, springs, reservoirs, lakes or mountain glaciers that have not passed through a public water supply system.

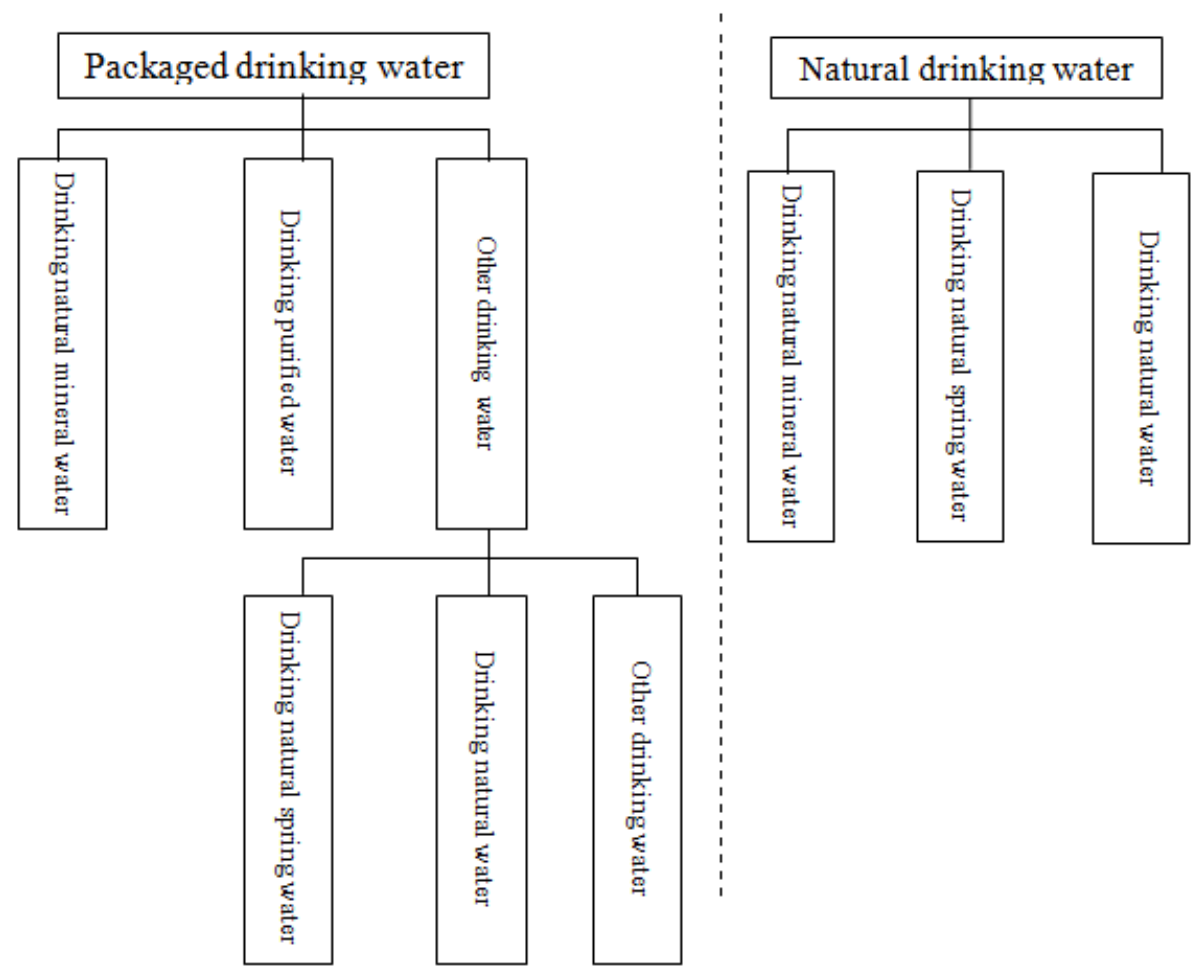

Fig. 1. Conceptual diagram of packaged drinking water and natural drinking water

\section{Overview of China's natural drinking water pre-production link standards}

The pre-production link of natural drinking water industry mainly includes investigation \& exploration, monitoring \& evaluation, comprehensive protection, development \& utilization of natural drinking water resources, and etc. At present, there are 8 relevant standards.

The investigation \& exploration of natural drinking water resources mainly refers to the identification of geological and hydrogeological conditions for the formation of natural drinking water through standardized geological exploration techniques, and the determination of the location of natural drinking water production wells and the boundary of protected areas. At present, there are 2 relevant national standards, namely, GB/T 11615-2010 The Code for Geological Exploration of Geothermal Resources and GB/T 13727-2016 The Code for Geological Exploration of Natural Mineral Water Resources. Among them, the former mainly stipulates the control degree of geological exploration of geothermal resources and the quality requirements of exploration works, and puts 
forward the geothermal resources, reserves calculation, fluid quality evaluation, and etc. The latter stipulates the technical requirements for geological exploration of water sources of natural mineral water resources, water quality testing and evaluation, calculation and evaluation of allowable exploitation amount, and protection \& dynamic monitoring of water sources. Existing standards can effectively reduce risks in resources development by delineating areas and water sources available for development and utilization through geological exploration, and determining reasonable development and utilization amount.

The monitoring and evaluation of natural drinking water resources mainly refers to the classification and evaluation of natural drinking water resources quality and dynamic monitoring of water resources environment through the conventional and unconventional indicator sets of natural drinking water resources and their thresholds. At present, there are 2 relevant national standards, including GB/T 14848-2017 Groundwater Quality Standard and Surface Water Environmental Quality Standard, and 2 industry standards, namely, HJ/T 164-2004 Technical Specifications for Environmental Monitoring of Groundwater and Technical Specifications Requirements for Monitoring of Surface Water and Waste Water. Among them, the Groundwater Quality Standard stipulates the evaluation indexes and limits of groundwater quality and classifies the groundwater. The Surface Water Environmental Quality Standard stipulates the items and limits to be controlled for water environmental quality and the methods of water quality evaluation and analysis. The Technical Specifications for Environmental Monitoring of Groundwater stipulates the groundwater monitoring point network, sample collection management, monitoring items and analysis methods.

The Comprehensive protection of natural drinking water resources refers to the prevention and control of pollution of natural drinking water sources and guarantee of environmental quality of water sources through a series of special protection measures. There are 4 related industry standards, namely, the HJ/T 338-2007 Technical Specification for the Division of Drinking Water Source Protection Areas, HJ/T 433-2008 Technical Requirements for Marking Drinking Water Source Protection Areas, HJ 773-2015 Technical Requirements for Environmental Protection for Standardized Construction of Centralized Drinking Water Sources, and HJ 774-2015 Technical Specification for Assessment of Environmental Protection Status of Centralized Drinking Water Sources. In addition, there is also 1 local standard, namely, DB44/T 749-2010 Technical Guideline for Delineating Source Water Protection Areas.Among them, the Technical Specification for the Division of Drinking Water Source Protection Areas stipulates the basic methods for the division of surface water drinking water source protection areas and groundwater drinking water source protection areas and the preparation of technical documents regarding the division of drinking water source protection areas. The Technical Requirements for Marking Drinking Water Source Protection Areas stipulates the requirements for marking types, contents and locations of drinking water source protection areas. The Technical Requirements for Environmental Protection for Standardized Construction of Centralized Drinking Water Sources stipulates the technical requirements for environmental protection such as the quantity and quality of drinking water sources, the construction of drinking water source protection areas and the remediation of protected areas, monitoring capabilities, risk prevention \& control and emergency response capabilities, and management measures. The Technical Specification for Assessment of Environmental Protection Status of Centralized Drinking Water Sources stipulates the technical methods for assessment of water quantity and quality of centralized drinking water sources, environmental management status of water sources and change trend.

The development and utilization of natural drinking water resources mainly refers to the sustainable utilization of natural drinking water resources and the maximization of resources value by evaluating the development and utilization potential of natural drinking water resources and standardizing the development and utilization process of natural drinking water resources.

Natural drinking water resources are an important branch of drinking water resources. Although drinking water resources have detailed specifications for water resources investigation \& exploration, monitoring \& evaluation, and comprehensive protection, the natural drinking water has more important natural ecological, economic \& social properties. Based on the drinking water resources standards, it is necessary to add standard guidelines for natural drinking water resources monitoring, 
natural drinking water source protection technology, and natural drinking water resources development and utilization, and provide the more effective and practical standards for preproduction links, which will lay a solid foundation for subsequent natural drinking water industry links.

\section{Overview of China's natural drinking water in-production link standards}

The in-production link in the production of natural drinking water industry mainly includes the production of packaging materials, manufacturing of processing equipment, production and processing of products, process quality control, and etc. At present, there are 38 relevant standards, 3 international standards, 22 national standards, 12 industry standards and 1 local standard.

The production of natural drinking water packaging materials mainly refers to the specifications of natural drinking water packaging materials, labels, sanitation, and etc., which are directly or indirectly provided to consumers. At present, there are 18 relevant standards, which mainly stipulates the drinking water packaging in terms of packaging materials, packaging marks, sanitation standards, and etc. For the packaging materials, the physical and chemical properties of the materials are strictly specified through various indexes in terms of the types of packaging containers, glass fiber containers, composite food packaging bags, and etc. The packaging label provides the requirements for the labels, ingredients, production date and shelf life of the packaged food. Hygienic standards provide the requirements for the sensory and physical and chemical indicators on food packaging bags.

The manufacturing of natural drinking water processing equipment refers to the manufacturing and use of equipment involved in each link of the natural drinking water processing process. At present, there are 1 international standard, 5 national standards and 7 industry standards, which are mainly set up for pipeline equipment, disinfection and filtration equipment, production line equipment, and etc. Among them, the pipeline equipment standard mainly stipulates its basic requirements, test methods, inspection rules and etc. The disinfection and filtration equipment standard provides the requirements for the basic parameters, inspection requirements, packaging and storage of the equipment. The production line equipment standard covers the working requirements, operation indexes and inspection requirements of filling, capping, sealing and other machines.

The production and processing of products refers to the standards required by the process design, production and processing, product assembly and other links involved in the whole process of natural drinking water from raw materials input to finished products output. At present, there is 1 national standard, the National Standard for Food Safety, Hygienic Code for the Production of Packaged Drinking Water, which ensures food safety in the production process by means of water treatment process control, chemical pollution control, microbial pollution control, and etc. In addition, there is also 1 existing industry standard, namely, Drinking Water Fluoride Removal Design Regulations, which stipulates the drinking water fluoride content standard, inspection method and technical standard.

The process quality control refers to the technical measures and management measures stipulated to make products meet the quality requirements. Currently, there are 1 international standard and 5 national standards, which are mainly related to the collection, processing $\&$ sales and corporate hygiene. Among them, the collection, processing \& sales stipulate the hygiene requirements, inspection rules and transportation \& storage of drinking natural mineral water sources and their products. Corporate hygiene stipulates the basic requirements and management guidelines for monitoring the quality of source water for the production of packaged drinking water, water source hygiene protection and source water collection.

The in-production link standard in natural drinking water products is the most important part of the whole natural drinking water industry standard system, which ensures that the products meet the required requirements. The in-production link standard in natural drinking water products is sorted out from four aspects: packaging material production, processing equipment manufacturing, product production and processing, and process quality control. The standard system in all aspects is relatively complete. In addition, the production \& processing of products and process quality control are also specially standardized for the production and sanitation of packaged drinking water including natural 
drinking water.

The in-production link standards of natural drinking water in China are as shown below:

The packaging materials production standards include: the national standard GB 19778-2005 Packaging Glass Containers-Release of Lead Cadmium Arsenic and Antimony-Permissible Limits, national standard GB/T 14354-2008 Food Containers of Glass Fiber Reinforced Unsaturated Polyester Resin, national standard GB 9683-1988 Hygienic Standard for Composite Laminated Food Packaging Bag, national standard GB/T 13663-2000 Polyethylene Pipes for Water Supply, national standard GB 4806.9-2016 National Food Safety Standard Metal Materials and Products for Food Contact, national standard GB 4806.7-2016 National Food Safety Standard Plastic Materials and Products for Food Contact, national standard GB 4806.6-2016 National Food Safety Standard-Plastic Resin used in Food-Contact, national standard GB 4806.4-2016 Hygienic Standard of Ceramics for Food Containers, national standard GB 7718-2011 National Food Safety Standard General Standard for the Labeling of Prepackaged Foods, national standard GB 16331-1996 Hygienic Standard of Nylon 6 Resins for Food Packaging Material, national standard GB 13115-1991 Hygienic Standard of Unsaturated Polyester Resin and Glass Fiber Reinforced Plastics Used as Food Containers and Packaging Materials, national standard GB 4806.1-1994 Hygienic Standard for Foodstuff Rubber Products, national standard GB/T 107892015 General Standard for Beverage, industry standard BB/T 0060-2012 Packaging Containers-Poly (Ethylene Terephthalate) Preform, industry standard QB 2460-1999 Polycarbonate (PC) Drinking Water Tank, industry standard QB/T 2665-2004 Heat-Resistant Polyethylene Terephthalate (PET) Bottle, industry standard QB/T 3531-1999 Composite Flexible Packing Materials for Liquid Food, local standard DB34/T 1790-2012 Technical Specification of Material Identification for Polycarbonate Drinking Water Bucket.

The processing equipment manufacturing standards include: the industry standard JB/T 12283-2015 Brass Castings for Drinking Water System Components, international standard ISO 24511-2007 Test Method for Extractability of Lead and Tin in Hard Polyvinyl Chloride (PVC) Drinking Water Pipes, industry standard QB/T 2754-2005 Liquid Quantitative Bottle Filler with Constant Volume, industry standard QB/T 1166-1991 Double Filter, industry standard QB/T 2869-2007 Bevearage PET Bottle Rinser-Filler-Twist-on (Screw-on) Capper, industry standard HG/T 4085-2009 Pressurized Fiberbunch Filter, national standard GB/T 24571-2009 Aseptic PET Bottles Cold-Filling Line, national standard GB/T 21359-2008 Stainless Steel Tube Threaded Couplings for the Food \& Water Industry, industry standard CJ/T 204-2000 Drinking Water Ultraviolet Disinfector, national standard GB/T 17219-1998 Standard for Hygienic Safety EvaEuation of Equipment and Protective Materials in Drinking Water, national standard GB/T 28605-2012 Rubber and Plastics Tubing and Hoses and Hose Assemblies for Drinking Water; national standard GB/T 28604-2012 Rubber Seals Used in LivingWater and Drinking-Water Supply Pipes and Fittings, industry standard QB/T2736-2005 Automatic Rinsing Filling and Capping Machine for Bottled Water-Drinks.

The product production and processing standards include: the national standards GB 19304-2018 National Food Safety Standard - Hygienic Standard for Packaged Drinking Water Production and industry standard CECS 46-1993 Design Standard for Removal of Fluorides from Drinking Water.

The process quality control include: the international standard ISO 24512-2007 Activities Relating to Drinking Water and Wastewater Services - Guidelines for the Management of Drinking Water Utilities and for the Assessment of Drinking Water Services, international standard CAC/RCP 33-2011 Recommended International Code of Hygienic Practice for the Collecting,Processing and Marketing of Natural Mineral Waters, national standard GB 14881-2013 National Food Safety Standard General Hygienic Regulation for Food Production, and national standard GB 16330-1996 Hygienic specifications of factory for drinking natural mineral water.

\section{Overview of China's natural drinking water post-production link standards}

The natural drinking water post-production link mainly includes inspection \& testing, storage \& logistics, allocation \& distribution, brand building and etc. There are 72 existing standards, including 3 international standards, 69 national standards, 11 local standards, 3 industry standards, 2 group standards and 2 enterprise standards.

The inspection \& testing refers to the inspection and testing of the specified parameters of the produced products by various quality control methods in the production process according to the technological requirements of the products, so as to achieve the purpose of controlling the product quality. At present, there are 57 standards, including 3 international standards, 40 national standards, 7 local standards, 3 industry standards, 2 group standards and 2 enterprise standards. It mainly stipulates the basic requirements, testing methods and index requirements of drinking water quality inspection, including sensory properties and physical indicators, metal indicators, pesticide indicators, microbial indicators and other testing methods.

The storage \& logistics refers to storage, keeping, loading \& unloading, handling and distribution of goods by using of the self-built or leased warehouses and places. Distribution \& allocation is a kind of commodity circulation mode from the perspective of the operation mode of commodity circulation. At present, there are 2 local standards related to natural drinking water storage \& logistics, 
which stipulates the graphic signs of natural drinking water packaging, transportation requirements and storage conditions. There are no standards directly related to the distribution $\&$ allocation of natural drinking water.

The brand building refers to the behavior of brand owners to plan, design, publicize and manage the brand, so as to add value to the products. At present, there are 4 relevant national standards and 2 local standards. It is mainly divided into brand value evaluation, regional brand cultivation and geographical indication products, among which the brand evaluation standard specifies the relevant requirements of product design value evaluation calculation model, calculation index, calculation process, and etc. The cultivation of regional brand is to design guidelines for the implementation of the brand management system through the theory and practice of regional brand building, so as to promote regional brand building. As a typical regional brand, geographical indication products can enhance the popularity of geographical indication products and bring into play the cohesion of industrial agglomeration by establishing calculation models in terms of product characteristics, industrial composition, regional distribution and industrial ranking.

The post-production link standard of natural drinking water industry is a key link to enhance the value of natural drinking water industry. It is necessary to guarantee the quality of natural drinking water products, dredge the product sales channels, and establish the brand value, by taking measures from the perspectives of inspection \& testing, storage \& logistics, distribution \& allocation, brand building and etc. The existing standards may better guarantee the post-production link of natural drinking water, but the inspection \& testing of special natural drinking water such as spring resources, drinking medical compound natural mineral water and other special natural drinking water needs to be strengthened in detail. We will increase the relevant regulations for the distribution \& allocation of natural drinking water, ensure the good flow of natural drinking water, study the regulations for the recycling of drinking water packaging bottles, and improve the last link of natural drinking water.

Table 1. China's natural drinking water post-production link standards

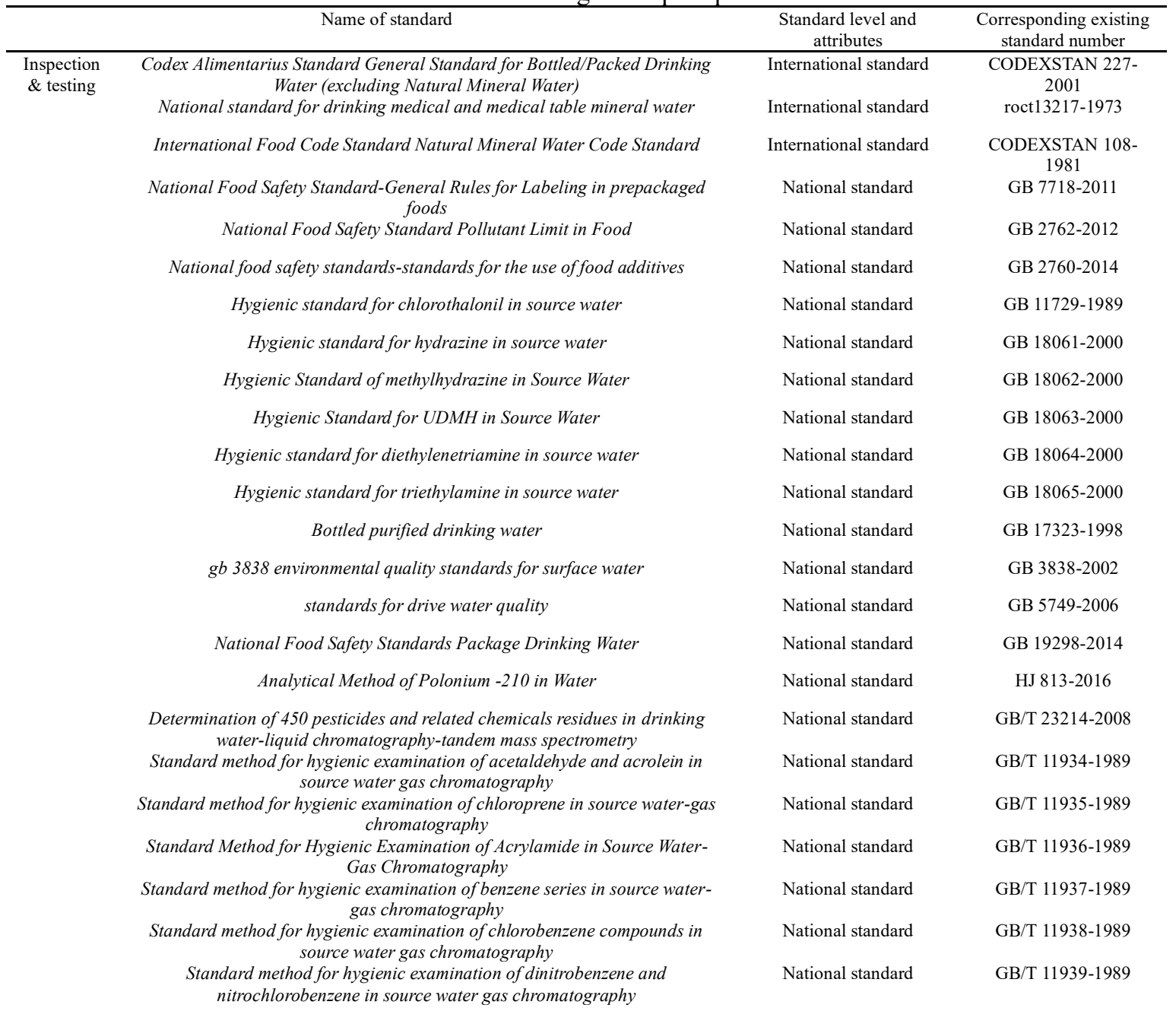


Standard Method for Hygienic Examination of Crotonaldehyde in Source Water-Gas Chromatography

Standard Method for Hygienic Examination of Sulfide in Source Water-Gas Chromatography

Standard Examination Methods for Drinking Water

Standard Examination Methods for Drinking Water

Standard test methods for drinking water-quality control for water quality

analysis
Standard test methods for drinking water-Sensory properties and physical indicators

Standard Examination Methods for Drinking Water

Standard Examination Methods for Drinking Water

Standard Examination Methods for Drinking Water

Standard Examination Methods for Drinking Water

Standard Examination Methods for Drinking Water

Standard Examination Methods for Drinking Water

Standard Examination Methods for Drinking Water

Standard Examination Methods for Drinking Water

Standard Examination Methods for Drinking Water

Hygienic standard for beryllium in drinking water

$$
\text { Drinking natural mineral water }
$$

Determination of Fluoride, Chlorine, Bromine Ion, Nitrate and Sulfate in Drinking Natural Mineral Water by Reversed Phase High Performance Liquid Chromatography

Testing methods for drinking natural mineral water

Green Food Packaging Drinking Water

Technical specification for division of drinking water source protection areas

Detection of Legionella in Drinking Water

Determination of Nitrate Nitrogen in Drinking Water by Ultraviolet Spectrophotometry

Determination of Cyanide in Drinking Water by Gas Chromatography

total soluble solid

Determination of Bromate Ion in Drinking Water-Ion Chromatography

Standard Examination Methods for Drinking Water

Bottles (barrels) contain drinking natural spring water (drinking mountain spring water)

Bottles and barrels (bags) contain drinking mountain spring water

Food Safety Standards for Nongfu Mountain Spring Enterprises Infant Drinking Natural Water

Lhasa Riduo Hot Spring Villa Co., Ltd. Enterprise Standard Drinking and Medical Compound Natural Mineral Water Tibet Drinking Natural Water

Tibet Everest Glacier Water Resources Development Co., Ltd. Enterprise Standard Tea Water

Storage \&

Guangdong Provincial Food Safety Local Standard Drinking Natural Mountain Spring Water

Guizhou Province Food Safety Local Standard Drinking Natural Spring Water

Brand Value Evaluation Wine, Beverage and Refined Tea Manufacturing

Brand Value Evaluation Food Processing and Manufacturing

Brand Value Evaluation of Geographical Indication Products

Geographical Indication Product Jilin Changbai Mountain Drinking Natural Mineral Water

Guidelines for Regional Brand Cultivation and Construction

Evaluation of Regional Brand Value

Geographical Indication Product Oncido Mineral Water

Geographical Indication Product Kedong Natural Soda Water
National standard

National standard

National standard

National standard

National standard

National standard

National standard

National standard

National standard

National standard

National standard

National standard

National standard

National standard

National standard

National standard

National standard

National standard

National standard

industry standard

Industry standard

Industry standard

Local standard

Local standard

Local standard

Local standard

Local standard

Local standard

Local standard

Enterprise standard

Enterprise standard

Group standard

Group standard

Local standard

Local standard

National standard

National standard

National standard

National standard

National plan

National plan

Local standard

Local standard
GB/T 11940-1989

GB/T 11941-1989

GB/T 5750.1-2006

GB/T 5750.2-2006

GB/T 5750.3-2006

GB/T 5750.4-2006

GB/T 5750.5-2006

GB/T 5750.6-2006

GB/T 5750.7-2006

GB/T 5750.8-2006

GB/T 5750.9-2006

GB/T 5750.10-2006

GB/T 5750.11-2006

GB/T 5750.12-2006

GB/T 5750.13-2006

GB 8161-1987

GB 8537-2008

GB/T 5009.167-2003

GB/T 8538-2008

NY/T 2980-2016

HJ/T 338-2007

SN/T 2528-2010

DB22/T 175-1998

DB22/T 176-1998

DB22/T 416-2005

DB 44/T417-2007

DB22/T 239-2000

DB53/ 118-2009

DB35/T 914-2009

Q/NFS0012S-2014

Q/LSRD001S-2015

T/ZTSXH001S-2016

Q/ZFBC00035-2015

DBS44/ 001-2011

DBS 52/008-2015

GB/T 31280-2014

GB/T 31047-2014

GB/T 36678-2018

GB 20349-2006

20150576-T-469

20150523-T-469

DB63/T 1347-2015

DB23/T 1727-2016

\section{Conclusion and outlook}

China is the world's largest consumer of bottled water, which grows at an alarming rate. Natural drinking water is an important branch of packaged drinking water. Sorting out the relevant standard system of natural drinking water industry is in favor of the rapid and healthy development of the 
industry. In this study, on one hand, the concept of natural drinking water is defined and classified through the existing standard classification and definition; On the other hand, the relevant standards of natural drinking water in the pre-production, in-production and post-production links are sorted out, and the types of standards in variable links are summarized to form an interlocking standard system. In addition, the weak links of natural drinking water industry standards are also pointed out targetedly. The establishment and improvement of a standard system for natural drinking water industry will reasonably standardize variable links of the industry, enhance the core competence of the natural water industry and maintain the sustainable development of the industry.

\section{Acknowledgment}

This article was funded by the Tibet Autonomous Region Science and Technology Program Project "Study on the Construction of Natural Drinking Water Standard System in Tibet Autonomous Region" (Project No.: Z2016R67F12).

\section{References}

[1] China Beverage Industry Association Survey Data [DB/OL], http://www.chinabeverage.org

[2] Ma Tingyu, Analysis of bottled water industry in China based on SCP paradigm[J]. Business Economics, volume (10), pp. 121-122+178, 2018.

[3] Liao Zhenyu, Cao Dongli, Zhang Hua, and Xiuyuan Zhao, Current situation and existing problems of packaged drinking water industry in China [J]. Journal of Food Safety and Quality Testing, volume 8 (03), pp. 737-741, 2017.

[4] Yuan Yiling, Zhu Peiwu, and Jin Luyan. Analysis and suggestions on current situation of packaging drinking water standards in China[J]. Popular Standardization, volume (10), pp. 5459, 2013.

[5] National food safety standard GB/T 10789-2015 Packaged Drinking Water [S].

[6] National standard GB8537-2008 Drinking Natural Mineral Water [S].

[7] National standard GB/T 10789-2015 General Rules for Beverages [S].

[8] T/ZTSXH001S-2016 Tibet Autonomous Region Group Standard Drinking Natural Water in Tibet $[\mathrm{S}]$. 